\title{
ОЦЕНКА СОСТОЯНИЯ СЕНОКОСНЫХ УГОДИЙ НА ОСНОВЕ НАЗЕМНОЙ И СПУТНИКОВОЙ СПЕКТРОМЕТРИИ*
}

A.A. Larko, I.Yu. Botvich, D.V. Emelyanov, N.A. Kononova

\section{THE ASSESSMENT OF THE STATE OF GRASSLANDS ON THE BASIS OF GROUND AND SATELLITE SPECTROMETRY}

Ларько Александр Александрович - вед. математик лаб. экологической информатики Института биосизики СО РАН - обособленного подразделения ФИЦ КНЦ СО РАН, г. Красноярск.

E-mail: lantar@inbox.ru

Ботвич Ирина Юрьевна - мл. науч. сотр. лаб. экологической инфрорматики Института биосизики СО РАН - обособленного подразделения ФИЦ КНЦ СО РАН, г. Красноярск.

E-mail: irina.pugacheva@mail.ru

Емельянов Дмитрий Владимирович - инженер лаб. экологической информатики Института биофизики СО РАН - обособленного подразделения ФИЦ КНЦ СО РАН, г. Красноярск.

E-mail: dima9526@gmail.com

Кононова Наталья Александровна - мл. науч. сотр. лаб. экологической инсоорматики Института биофизики СО РАН - обособленного подразделения ФИЦ КНЦ СО РАН, г. Красноярск.

E-mail: nata_slyusar@mail.ru

В работе рассмотрены исследования по изучению структуры и спектральных характеристик травянистых растительных сообществ сенокосных угодий в условиях Красноярской лесостепи. Исследования проводились в течение вегетационных сезонов 2018-2019 годов на сельскохозяйственных угодьях Емельяновского района Красноярского края (п. Минино). В результате анализа спутниковых данных (Sentinel-2) и данных наземной спектрометрии (на базе спектрорадиометра Spectral Evolution PSR 1100F) выделены тестовые участки, размер и структура травостоя которых позволяют получить статистически достоверные данные. С иелью наземной верификации данных проведены гео-
Larko Alexander Alexandrovich - Leading Mathematician, Lab. of Ecological Informatics, Institute of Biophysics SB RAS - Separate Division of RC KRC Branch SB RAS, Krasnoyarsk.

E-mail: lantar@inbox.ru

Botvich Irina Yuryevna - Junior Staff Scientist, Lab. of Ecological Informatics, Institute of Biophysics SB RAS - Separate Division of RC KRC Branch SB RAS, Krasnoyarsk.

E-mail: irina.pugacheva@mail.ru

Emelyanov Dmitry Vladimirovich - Engineer, Lab. of Ecological Informatics, Institute of Biophysics SB RAS - Separate Division of RC KRC Branch SB RAS, Krasnoyarsk.

E-mail: dima9526@gmail.com

Kononova Natalya Alexandrovna - Junior Staff Scientist, Lab. of Ecological Informatics, Institute of Biophysics SB RAS - Separate Division of RC KRC Branch SB RAS, Krasnoyarsk.

E-mail: nata_slyusar@mail.ru

ботанические описания растительности. Проведенные исследования показывают, что спектральные характеристики сенокосных угодий в течение периода вегетации существенно отличаются от земель с другим типом использования. Согласно спутниковым данным, в раннелетний этап вегетационного сезона значения NDVI на тестовых участках с высокой степенью сходства видового состава идентичны. В результате проведенного на одном из участков сенокошения значения NDVI уменьшились на $35 \%$, что связано с изъятием большей части надземной фитомассы растений. Продуктивность сырой фритомассы сообществ после уборки сена составила $41,5 \pm 8,9$ 2/M², что в 16 раз меньше первона-

\footnotetext{
* Исследование выполнено при финансовой поддержке РФФИ, Правительства Красноярского края, Красноярского краевого фонда науки в рамках научного проекта № 18-416-243002 р_мол_а.
} 
чальной величины. Анализ данных, полученных методами наземной спектрометрии, показал, что спектры отражения растительности сенокосных угодий имеют схожую динамику со спектрами, полученными спутниковыми системами, что свидетельствует о достоверности результатов и возможности применения спутниковых данных для больших территорий. В результате разработан новый подход для дешифрирования спутниковой инфрормации с иелью оперативного определения грании растительных сообществ (сенокосных угодий). Данный подход верифицирован и протестирован по данным наземных исследований на территории Красноярского края.

Ключевые слова: дистанционное зондирование, наземная спектрометрия, NDVI, Sentinel-2, сенокосы, Красноярская лесостепь.

The study of the structure and spectral characteristics of herbaceous plant communities of grasslands of Krasnoyarsk Region was carried out. The researches were carried out during vegetation seasons of 2018-2019 on agricultural land of Emelyanovo district of Krasnoyarsk Region (s. Minino). As a result of the analysis of satellite data (Sentinel-2) and ground-based spectrometry data (based on the Spectral Evolution PSR 1100F spectroradiometer), test sites, their size and structure of herbage allowed obtaining statistically reliable data. Geobotanical descriptions of vegetation for ground-based data verification were carried out. Performed researches showed that spectral characteristics of grasslands during vegetation season significantly differed from the lands with another type of land use. According to satellite data, in early-summer phase of vegetation season, NDVI values were identical in test plots with similarity in species composition. As a result of the mowing carried out on one of the plots NDVI values decreased by $35 \%$ which was connected with the withdrawal of the most part of the plants' above-ground phytomass. The productivity of wet phytomass communities after hay harvesting was $41.5 \pm 8.9 \mathrm{~g} / \mathrm{m}^{2}$, being 16 times less than original value. The analysis of the data obtained by ground-based spectrometry methods showed that the reflection spectra of hayfields vegetation had similar dynamics with the spectra obtained by satellite systems, which indicated the reliability of the results and the possibility of using satellite data for large areas. As a result new approach was developed for decoding satellite information for the purpose of expeditious delimitation of vegetable communities (haying grounds). This approach had been verified and tested according to land research in Krasnoyarsk Region.

Keywords: remote sensing, ground-based spectrometry, NDVI, Sentinel-2, hayfields, Krasnoyarsk forest-steppe.

Введение. Сенокосные земли являются важным кормовым ресурсом для животноводства [7]. Задача отслеживания изменений структуры и состояния полей, предназначенных для скашивания, является составляющей проблемы обновления карт состава сельскохозяйственных площадей. Оценить изменение площадей сенокосных угодий, а также отследить скорость возобновления растительности при двуукосном режиме скашивания возможно методом прямых наблюдений, что при больших площадях является трудоемкой задачей и требует больших временных затрат.

Современные методы спутникового мониторинга активно применяются для нужд сельского хозяйства и позволяют успешно и оперативно регистрировать изменение площади и состояния земель на больших территориях $[5,11]$. Большинство исследований дистанционными методами направлено на изучение пастбищных угодий и их деградацию [3-5, 10], в то время как анализу сенокосных угодий уделено значительно меньше внимания [7, 9]. На сегодняшний день для анализа изменений спектральных характеристик растительности применяют полевые, авиационные и космические спектрорадиометры $[6,8]$. Использование сразу нескольких видов съемки позволяет получить более точные результаты.

Цель исследований. Изучение спектральных характеристик травянистых растительных сообществ сенокосных угодий по наземным и спутниковым данным и разработка метода их дешифрирования.

Задачи исследований: определение спектральных коэффициентов яркости растительности до и после сенокошения, полученных наземным спектометрированием и спутниковыми данными. 
Объект и методы исследований. Объектом настоящего исследования являются сельскохозяйственные угодья центральной части Красноярского края, предназначенные для сенокошения. Исследования выполнены в течение вегетационных сезонов 2018-2019 годов. Участки располагаются в пределах Красноярской лесостепи. Красноярская лесостепь имеет прохладный режим погоды, достаточное увлажнение (гидротермический коэфффициент 1,2-1,6). Период вегетации растений 130-150 дней с температурой выше 10 ㄷ продолжается 100-105 дней, безморозный период 90 дней [1]. Выбор тестовых участков обусловлен размером тестового полигона, который должен обеспечивать возможность проведения большого количества спутниковых и наземных измерений для получения статистически достоверного результата $[4,6]$.

Основным методическим подходом при проведении исследований является комплексное использование спутниковой и наземной спектрометрии, а также единовременных геоботанических описаний, что существенно повышает репрезентативность результата.

1. Спутниковые данные. Использованы данные спутниковой системы Sentinel-2. При обработке спутниковых данных выявлены спектральные характеристики растительных сообществ сенокосов. Выполнен расчет спектральных индексов NDVI (Normalized Difference Vegetation Index). Вся полученная информация структурирована в созданный банк данных изучаемых растительных сообществ, который включает в себя наборы временных рядов вегетационных индексов для различных фенособытий по данным спутниковых сенсоров (20002019 гг.).

2. Наземное спектрометрирование. Внутрисезонные изменения спектральных характеристик растительных сообществ учтены с помощью спектрорадиометра Spectral Evolution PSR $1100 \mathrm{~F}$, который рассчитывает коэфффициент спектральной яркости (КСЯ) объекта. КСЯ - это отношение яркости исследуемой поверхности в интервале длин волн к яркости идеально рассеивающей ортотропной поверхности в том же направлении, находящейся в тех же условиях освещения. Спектральные измерения проводились в период с 10 до 15 часов местного времени.

3. Геоботанические исследования. По традиционным методикам определена структура фитоценозов: видовой состав, проективное покрытие травостоя (общее и отдельных видов). Для верификации данных дистанционного зондирования в пределах каждой пробной площадки определена сырая надземная фитомасса. Для определения урожайности были взяты уко-

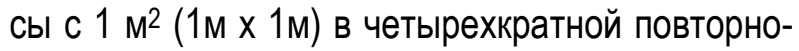
сти. Все полученные результаты пересчитывались в г/M². Полученные данные обработаны статистически с использованием пакета MS Excel 2013.

Результаты исследований и их обсуждение. Спектральные характеристики растительного покрова зависят главным образом от его видового состава, проективного покрытия, горизонтальной и вертикальной структуры. Особое значение имеет сезон года, а также внутрисезонные фенологические изменения растительности, начало и окончание основных фенофаз $[4,5]$. На землях сельскохозяйственного назначения спектральный портрет растительности зависит от вида хозяйственного использования. Для сенокосных угодий характерно периодическое скашивание растений, достигших определенной фазы развития и имеющих на момент уборки максимальную хозяйственную ценность [2]. До скашивания высота отдельных видов может превышать один метр, в то время как после сенокошения на почве остается относительно равномерный растительный покров высотой, как правило, до 10 см. Проективное покрытие растительности значительно снижается. Такие изменения в структуре сильно влияют на спектральные показатели покрова, что позволяет провести их идентификацию дистанционными методами.

С целью оценки спектральных характеристик травянистых растительных сообществ сенокосных угодий был исследован тестовый участок, который отвечают критериям отбора (табл.). 
Вестник КрасТАУ. 2020. № 2

Характеристика тестовых участков сенокосных угодий Красноярской лесостепи

\begin{tabular}{|c|c|c|c|c|}
\hline $\begin{array}{c}\text { Местоположение (рас- } \\
\text { тительность) }\end{array}$ & Координаты & $\begin{array}{l}\text { Число видов } \\
\text { на } 100 \mathrm{M}^{2} \text {, шт. }\end{array}$ & $\begin{array}{l}\text { Проективное } \\
\text { покрытие, \% }\end{array}$ & $\begin{array}{c}\text { Сырая } \\
\text { фитомасса, г/м² }\end{array}$ \\
\hline $\begin{array}{c}\text { Участок. } \\
\text { п. Минино (пырейная } \\
\text { залежь 3-5 лет) }\end{array}$ & $\begin{array}{l}\text { N } 56^{\circ} 3^{\prime} 56.37^{\prime \prime} \\
\text { E } 92^{\circ} 39^{\prime} 22.04^{\prime \prime}\end{array}$ & 36 & $65-85$ & $\frac{686.8 \pm 152.2^{*}}{41.5 \pm 8.9}$ \\
\hline
\end{tabular}

* в числителе - фитомасса до сенокошения; в знаменателе - фитомасса после сенокошения.

Тестовый участок расположен в Емельяновском районе в окрестностях п. Минино. Участок представляет собой залежь возрастом 3-5 лет. Территория относится к сенокосным землям. Злаковую основу составляет мезофит пырей ползучий Elytrigia repens (L.) Nevski с проективным покрытием до 50 \%. Разнотравье представлено сорными видами: бодяк полевой Cirsium arvense (L.) Scop., одуванчик лекарственный Taraxacum officinale F.H. Wigg., гулявник Лезеля Sisymbrium loeselii L. На участке отмечены монодоминантные полосы донника лекарственного Melilotus officinalis (L.) Pall., горошка приятного Vicia cracca L. c проективным покры- тием до $60 \%$, что существенно увеличивает кормовую ценность травостоя $[2,6]$.

Для тестовых участков получен набор данных спутниковых систем Sentinel-2 с пространственным разрешением 10-250 м. Проведена предварительная и тематическая обработка данных спутниковых систем Sentinel-2 для выявления особенностей фенологического поведения изучаемых растительных сообществ в условиях разного режима использования. В результате обработки спутниковых данных установлено, что значения NDVI травостоя в результате сенокошения уменьшаются на $35 \%$ и более (рис. 1).

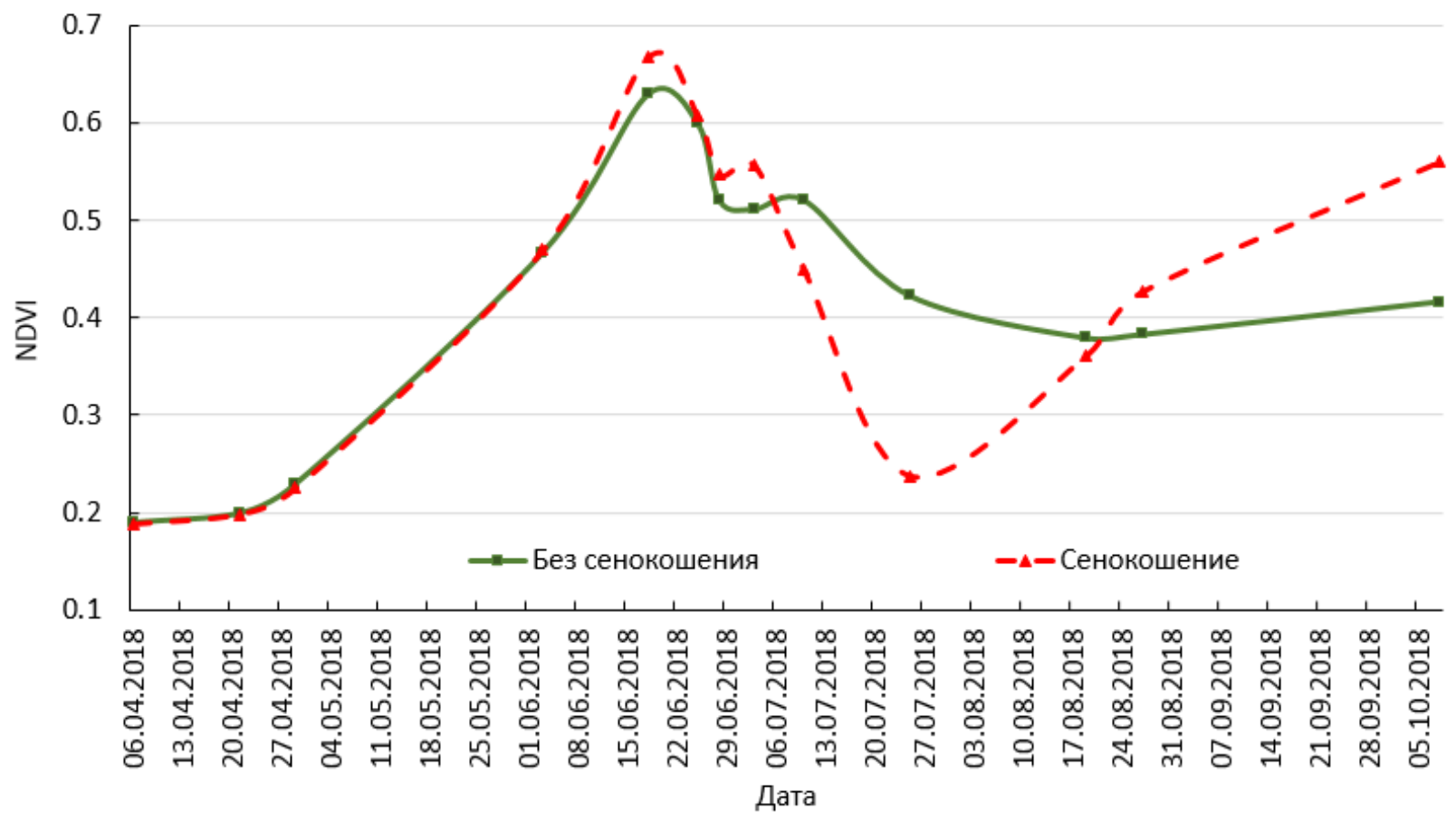

Puc.1. Динамика NDVI по данным Sentinel-2 (2018 г.) 
На рисунке 1 показана внутрисезонная динамика NDVI, полученная на основе спутниковых данных. В результате полевых исследований рассмотрено два участка, имеющих схожий видовой состав растительности. Участки располагались в территориальной близости друг от друга, но отличались по характеру использования. Первый участок (без сенокошения) в течение всего вегетационного сезона 2018 года не использовался в качестве сенокосов. Второй участок (сенокошение) был скошен. За период наблюдения в раннелетний этап вегетационного сезона значения NDVI на тестовых участках идентичны, что объясняется высокой степенью сходства видового состава. Доминирующий на обоих участках злак пырей ползучий формирует достаточно плотный травостой. Среднее проективное покрытие доминанта составляет 50 \%, в то же время на отдельных учетных площадках покрытие пырея достигает 80 \%, что обуславливает высокие показатели NDVI. В середине июня отмечается максимум накопления сырой надземной фитомассы доминирующих видов. В начале июля на одном из участков проходил сенокос, что существенно отразилось на спектральных характеристиках растительности.
Значения NDVI в этот период закономерно уменьшились, что связано с изъятием большей части надземной фритомассы растений. Продуктивность сообществ после уборки сена соста-

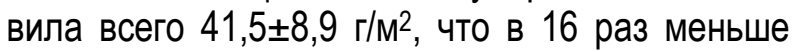
первоначальной величины (см. табл.). Значения NDVI растительного покрова участка, на котором сенокошение не проводилось, соответствуют классическому ходу френологического изменения травянистых растений по мере изменения сезона года.

Преимуществом использования спутниковых данных при оценке состояния сельскохозяйственных угодий является единовременный охват больших площадей. Однако спутниковые изображения низкого и среднего пространственного разрешения зачастую включают пиксели, не относящиеся к изучаемым объектам, а также участки, включающие различные атмосферные помехи. Данные фракты не позволяют достоверно идентифицировать требуемые сельскохозяйственные территории и провести качественную классификацию объектов. Для верификации данных, полученных со спутника, и исключения ошибок при их анализе актуально использовать методы наземной спектрометрии.

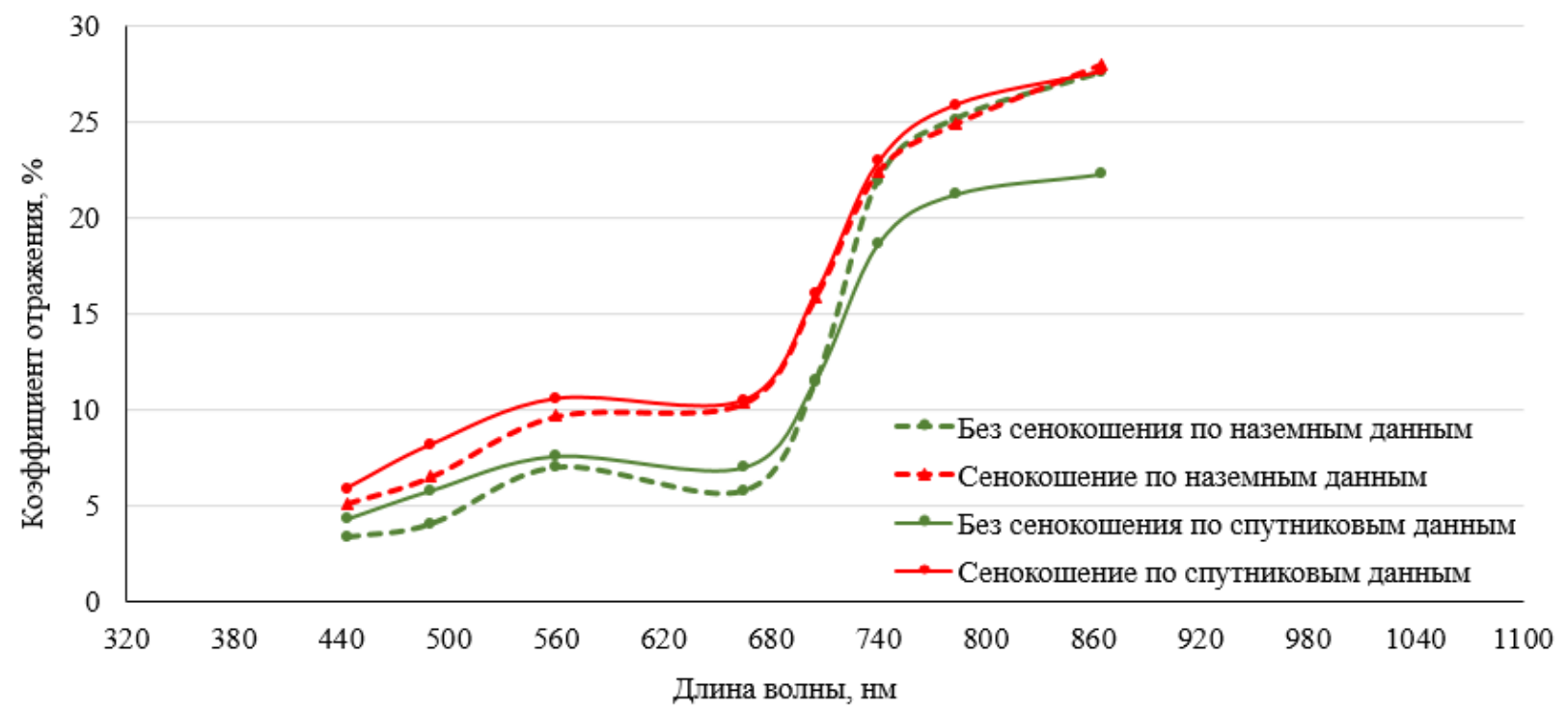

Puc. 2. Сравнение спектров отражения растений тестовых участков с сенокошением и без сенокошения, полученных по наземным и спутниковым данным

В результате проведенных полевых работ на тестовых участках показано, что спектры отражения растительности сенокосных угодий, по- лученные методами наземной спектрометрии, имеют схожую динамику со спектрами, полученными спутниковыми системами. Следует отме- 
тить, что спектры растительности на сенокосных землях практически полностью идентичны при использовании обоих видов съемки. Высокая степень сходства может быть обусловлена особенностью процесса сенокошения, при котором структурные характеристики растительности изменяются быстро и одновременно на больших площадях. Подобные изменения хорошо идентифицируются с помощью спутников и закономерно подтверждаются при наземной съемке. Спектры отражения растительности, произрастающей на участках, на которых сенокошение не проводилось, имеют более существенные отличия при применении разных видов съемки. В видимом диапазоне $(\lambda=400-700$ нм) спектры отражения растительности участков, полученные со спутника и наземными измерениями, существенно не отличаются, что связано с равномерным пространственным распределением травостоя. В то же время в ближнем инфрракрасном диапазоне $(\lambda=700-1300$ нм) величина коэфффициента отражения, полученного по наземным данным, заметно выше. Отражение в ближнем инфракрасном диапазоне характеризует структуру поверхности и содержание воды в тканях, поэтому рост значения коэфффициента отражения, вероятно, связан с более высокой детализацией наземных данных. Наземные спектры, в отличие от спутниковых, учитывают не только преобладающий аспект растительности на территории, но и отдельные особи растений, которые, в зависимости от видовой принадлежности, могут иметь существенные отличия в морфологическом и физиологическом плане.

Выводы. Проведение комплексного анализа геоботанических, наземных и спутниковых спектрометрических данных исследуемых тестовых территорий позволило выявить особенности изменений спектральных характеристик растительных сообществ, которые используются в качестве сенокосов. Определены отличия спектральных характеристик сенокосных угодий от угодий с другим типом использования в течение периода вегетации. В результате работ разработан новый подход для дешифрирования спутниковой информации с целью оперативного определения границ растительных сообществ (сенокосных угодий). Данный подход верифицирован и протестирован по данным наземных ис- следований на территории Красноярского края. Дальнейшая разработка данного метода позволит получать ежегодные карты растительного покрова с пространственным разрешением 250 м (по данным MODIS) и более высокого пространственного разрешения 10-20 метров (по данным Sentinel-2).

\section{Литература}

1. Антипова E.M. Флора внутриконтинентальных островных лесостепей Средней Сибири. - Красноярск, 2012. - 667 с.

2. Байкалова Л.П., Кожухова Е.В. Возделывание злаково-бобовых травосмесей как оптимизация урожайности среднесрочных сенокосов // Вестник КрасГАУ. - 2013. - № 5. - C. 68-74.

3. Блохин Д.Ю., Незамов В.И. Оценка продуктивности пастбищ на землях лесного фонда при помощи материалов дистанционного зондирования Земли // Вестник КрасГАУ. 2010. - № 5. - C. 24-28.

4. Бэкмухамедов Н.Э., Муратова Н.P., Северская С.М. Спектральные характеристики наиболее распространенных типов пастбищ Южного Прибалхашья // Гидрометеорология и экология. - 2013. - № 1. - С. 4451.

5. Государственный доклад о состоянии и охране окружающей среды в Красноярском крае за 2016 год. - Красноярск, 2017.

6. Золотокрылин А.Н., Титкова Т.Б., Уланова С.C. [и др.]. Наземные и спутниковые исследования продуктивности пастбищ Республики Калмыкии с различной степенью деградации растительных сообществ // Аридные экосистемы. - 2013. - Т. 19. - № 4 (57). - C. 31-39.

7. Кононова Н.А., Ларько А.А, Емельянов Д.В. [и др.]. Оценка состояния сенокосных угодий Красноярского края на основе наземной спектрометрии // Вестник КрасГАУ. 2019. - № 2. - C. 31-37.

8. Родионова А.В., Тебердиев Д.М. Продуктивность долголетнего сеяного сенокоса и плодородие дерново-подзолистых почв // Успехи современной науки. - 2017. - Т.1, № 10. - С. 178-183. 
9. Терехин Э.А. Сезонная динамика NDVI многолетних трав и ее использование для типизации их посевов на территории Белгородской области // Современные проблемы дистанционного зондирования Земли из космоса. - 2015. - T. 12, № 1. - С. 9-17.

10. Bomanowska A., Adamowski W., Kwiecień K., Rewicz $A$. The effects of different mowing regimes on diversity of grasses in lowland meadows // Turk J Bot (2019) 43: 80-89.

11. Punalekara S.M., Verhoefa A., Quaifeb T.L., Humphriesc D., Berminghamd L., Reynolds C.K. Application of Sentinel-2A data for pasture biomass monitoring using a physically based radiative transfer model // Remote Sensing of Environment 218 (2018) 207-220.

\section{Literatura}

1. Antipova E.M. Flora vnutrikontinental'nyh ostrovnyh lesostepej Srednej Sibiri. - Krasnoyarsk, 2012. - $667 \mathrm{~s}$.

2. Bajkalova L.P., Kozhuhova E.V. Vozdelyvanie zlakovo-bobovyh travosmesej kak optimizaciya urozhajnosti srednesrochnyh senokosov // Vestnik KrasGAU. - 2013. № 5. - S. 68-74.

3. Blohin D.YU., Nezamov V.I. Ocenka produktivnosti pastbishch na zemlyah lesnogo fonda pri pomoshchi materialov distancionnogo zondirovaniya Zemli // Vestnik KrasGAU. - 2010. - № 5. - S. 24-28.

4. Bekmuhamedov N.E., Muratova N.R., Severskaya S.M. Spektral'nye harakteristiki naibolee rasprostranennyh tipov pastbishch YUzhnogo Pribalhash'ya // Gidrometeorologiya i ekologiya. - 2013. - № 1. - S. 44-51.
5. Gosudarstvennyj doklad o sostoyanii i ohrane okruzhayushchej sredy v Krasnoyarskom krae za 2016 god. - Krasnoyarsk, 2017.

6. Zolotokrylin A.N., Titkova T.B., Ulanova S.S. [i dr.]. Nazemnye i sputnikovye issledovaniya produktivnosti pastbishch Respubliki Kalmykii s razlichnoj stepen'yu degradacii rastitel'nyh soobshchestv // Aridnye ekosistemy. - 2013. T. 19. - № 4 (57). - S. 31-39.

7. Kononova N.A., Lar'ko A.A, Emel'yanov D.V. [i dr.]. Ocenka sostoyaniya senokosnyh ugodij Krasnoyarskogo kraya na osnove nazemnoj spektrometrii // Vestnik KrasGAU. - 2019. № 2. - S. 31-37.

8. Rodionova A.V., Teberdiev D.M. Produktivnost' dolgoletnego seyanogo senokosa i plodorodie dernovo-podzolistyh pochv /I Uspekhi sovremennoj nauki. - 2017. - T.1, № 10. - S. 178-183.

9. Terekhin E.A. Sezonnaya dinamika NDVI mnogoletnih trav i ee ispol'zovanie dlya tipizacii in posevov na territorii Belgorodskoj oblasti // Sovremennye problemy distancionnogo zondirovaniya Zemli iz kosmosa. - 2015. - T. 12, № 1. - S. 9-17.

10. Bomanowska A., Adamowski W., Kwiecień K., Rewicz $A$. The effects of different mowing regimes on diversity of grasses in lowland meadows // Turk J Bot (2019) 43: 80-89.

11. Punalekara S.M., Verhoefa A., Quaifeb T.L., Humphriesc D., Berminghamd L., Reynolds C.K. Application of Sentinel-2A data for pasture biomass monitoring using a physically based radiative transfer model // Remote Sensing of Environment 218 (2018) 207-220. 